\title{
Normal spontaneous vaginal delivery after transcervical radiofrequency ablation of uterine fibroids: a case report
}

This article was published in the following Dove Press journal: International Journal of Women's Health

\author{
Ralf Bends' \\ David B Toub2,3 \\ Thomas Römer' \\ 'Department of Obstetrics and \\ Gynecology, Evangelisches Klinikum \\ Köln-Weyertal, Köln, Germany; \\ ${ }^{2}$ Department of Obstetrics and \\ Gynecology, Albert Einstein \\ Medical Center, Philadelphia PA, \\ USA; ${ }^{3}$ Medical Affairs, Gynesonics, \\ Redwood City, CA, USA
}

\begin{abstract}
Transcervical radiofrequency ablation of uterine fibroids was performed on a patient in Germany, who subsequently conceived. This is the first report of a normal spontaneous vaginal delivery after fibroid ablation with the Sonata ${ }^{\circledR}$ System.
\end{abstract}

Keywords: Sonata ${ }^{\circledR}$ System, uterine fibroid

\section{Introduction}

Transcervical delivery of radiofrequency (RF) energy to uterine fibroids has been reported and employs concurrent imaging to ablate specific fibroids. ${ }^{1-4}$ A CE marked device, the Sonata ${ }^{\circledR}$ System (Figure 1), is unique in that it integrates intrauterine sonography with RF ablation in a single handheld device. A graphical interface (SMART Guide ${ }^{\mathrm{TM}}$ ) depicts the user-selected deployment position of the RF electrodes and associated ablation, enabling the operator to determine the optimal size and position of each ablation within the fibroid, while maintaining thermal energy within the uterine serosal margin. Published safety and clinical efficacy results for the Sonata System have been positive, and there is a growing literature base for pregnancy after RF ablation in general, and Sonata specifically. ${ }^{1,5,6}$ This is a report of a recent experience with pregnancy and delivery after transcervical RF ablation with the Sonata System at a community hospital in Köln, Germany.

\section{Case}

A 33-year-old Gravida 1, Para 0 patient presented with heavy menstrual bleeding attributable to uterine fibroids. Transvaginal sonography revealed a $28 \mathrm{~mm}$ submucous fibroid (International Federation of Gynecology and Obstetrics [FIGO] type 2) in the left anterior uterine wall. After considering options including hysteroscopic myomectomy, the patient expressed a desire for transcervical RF ablation with the Sonata System, and this was performed under general anesthesia.

Intraoperative intrauterine sonography (performed with the integrated Sonata intrauterine ultrasound probe) confirmed the FIGO type 2 myoma measuring $27 \times 23 \mathrm{~mm}$. A $25 \times 35 \mathrm{~mm}$ ablation zone was placed in the fibroid. This was accomplished using the Sonata System's graphical overlay to display the location and boundary of the ablation prior to deployment of needle electrodes into the fibroid. After deployment of needle electrodes and confirming safe placement within the uterine serosal margins, RF energy was activated; total time at temperature $\left(105^{\circ} \mathrm{C}\right)$ was 1 minute 50 seconds.
Correspondence: Ralf Bends

Department of Obstetrics and

Gynecology, Evangelisches Klinikum

Köln-Weyertal, Weyertal 76, 5093

Köln, Germany

Tel +4922147932137

Fax +4922I 4792566

Email ralf.bends@evk-koeln.de 


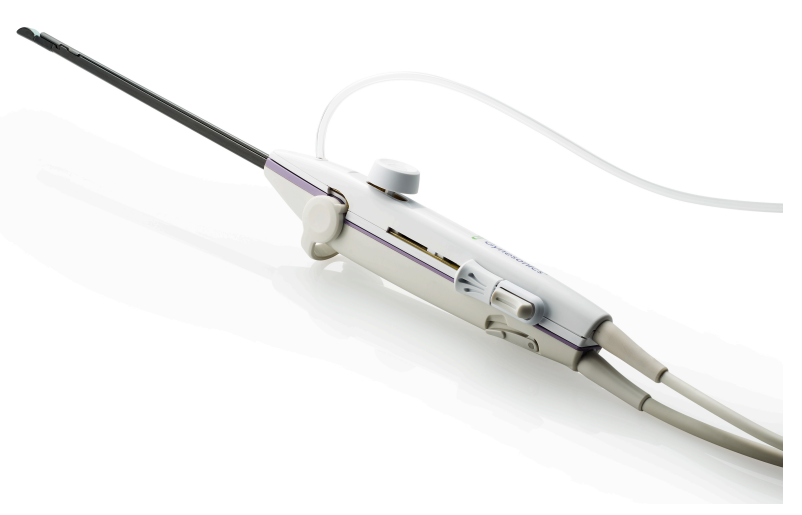

Figure I The Sonata ${ }^{\circledR}$ System Treatment Device.

There were no intraoperative complications. Besides transient postoperative complaints such as mild uterine cramping and minimal bleeding likely related to a gradual fibroid sloughing within the endometrial cavity, there were no adverse symptoms reported. Two weeks postoperatively, a contrast-enhanced magnetic resonance study indicated that $60 \%$ of the fibroid was no longer perfused. A follow-up imaging study after 24 months revealed no residual fibroid and the patient noted eumenorrhea.

Thirty-three months post ablation, the patient noted secondary amenorrhea and was confirmed to be pregnant. After an unremarkable antenatal period, the patient went into labor at 39 weeks of gestation and had a normal spontaneous vaginal delivery of a liveborn female infant with Apgar scores of $8^{1 / 9} 9^{5} / 10^{10}$ and a birth weight of 3,670 g. There were no complications.

\section{Discussion}

While myomectomy remains a standard treatment for women with symptomatic fibroids who desire pregnancy, there is a growing literature base reporting positive outcomes for pregnancy after fibroid ablation with both RF energy and focused ultrasound. ${ }^{5-11}$ A 2017 systematic review by Keltz et al noted 20 reported cases of pregnancy after RF ablation of uterine fibroids. ${ }^{6}$ As many of these involved patients who participated in research protocols that excluded women with a desire for fertility, seven of these pregnancies were managed with therapeutic abortion. Of the 13 remaining pregnancies, there were 12 full-term deliveries (nine by Cesarean section) and one spontaneous abortion, with a single reported perinatal complication of a fibroid expulsion associated with postpartum hemorrhage. While the number of reported pregnancies after RF ablation of uterine fibroids remains small, there are no reports of uterine rupture, abnormal placentation, or prematurity.
The Sonata System, as it incorporates high-resolution intrauterine sonography with a delivery system for RF energy, can allow clinicians to attempt to spare adjacent myometrium and endometrium from thermal injury. Nonetheless, fibroid ablation with RF energy remains investigational with regard to women who desire fertility. It should be noted, however, that fibroid ablation with focused ultrasound is approved for use in women who desire fertility in both the USA and the UK, based on accumulated clinical experience with posttreatment pregnancy as reported in the clinical literature. Thus, it is of interest to report on the continued experience of women who continue with their pregnancies after fibroid treatment with RF ablation.

The pregnancy reported in this paper resulted in the first known vaginal delivery after transcervical RF ablation with the Sonata System, and it is the first such delivery in Germany. A previously reported pregnancy from the FAST-EU study in Mexico involved an elective repeat Cesarean section. ${ }^{5}$ A global registry trial (SAGE) is in progress to accumulate data on additional pregnancies after treatment with the Sonata System, and another study (the OPEN Clinical Trial) is evaluating the status of the endometrial cavity with regard to adhesiogenesis status post transcervical RF ablation.

\section{Conclusion}

This is the first report of a normal spontaneous vaginal delivery at term following fibroid ablation with the Sonata System. While this and other reports are encouraging, additional clinical evidence is needed to assess the safety and feasibility of pregnancy after RF ablation of uterine fibroids, in general.

\section{Disclosure}

RB and TR are consultants for Gynesonics, Inc., the manufacturer of the Sonata System. DBT is the Medical Director at Gynesonics. The authors report no other conflicts of interest in this work.

\section{References}

1. Brölmann H, Bongers M, Garza-Leal JG, et al. The FAST-EU trial: 12-month clinical outcomes of women after intrauterine sonographyguided transcervical radiofrequency ablation of uterine fibroids. Gynecol Surg. 2016;13(1):27-35.

2. Cho HH, Kim JH, Kim MR. Transvaginal radiofrequency thermal ablation: a day-care approach to symptomatic uterine myomas. Aust $N Z J$ Obstet Gynaecol. 2008;48(3):296-301.

3. Kim CH, Kim SR, Lee HA, et al. Transvaginal ultrasound-guided radiofrequency myolysis for uterine myomas. Hum Reprod. 2011; 26(3):559-563.

4. Toub DB. A new paradigm for uterine fibroid treatment: transcervical, intrauterine sonography-guided radiofrequency ablation of uterine fibroids with the Sonata System. Curr Obstet Gynecol Rep. 2017;6(1): $67-73$. 
5. Garza-Leal JG, León IH, Toub D. Pregnancy after transcervical radiofrequency ablation guided by intrauterine sonography: case report. Gynecol Surg. 2014;11(2):145-149.

6. Keltz J, Levie M, Chudnoff S. Pregnancy outcomes following direct uterine fibroid thermal ablation: a review of the literature. $J$ Minim Invasive Gynecol. 2017;24(4):538-545.

7. Qin J, Chen JY, Zhao WP, et al. Outcome of unintended pregnancy after ultrasound-guided high-intensity focused ultrasound ablation of uterine fibroids. Int J Gynaecol Obstet. 2012;117(3):273-277.

8. Rabinovici J, David M, Fukunishi H, et al. Pregnancy outcome after magnetic resonance-guided focused ultrasound surgery (MRgFUS) for conservative treatment of uterine fibroids. Fertil Steril. 2010;93(1): 199-209.
9. Zou M, Chen L, Wu C, Hu C, Xiong Y. Pregnancy outcomes in patients with uterine fibroids treated with ultrasound-guided high-intensity focused ultrasound. BJOG. 2017;124(Suppl 3):30-35.

10. Berman JM, Bolnick JM, Pemueller RR, Garza Leal JG. Reproductive outcomes in women following radiofrequency volumetric thermal ablation of symptomatic fibroids. A retrospective case series analysis. J Reprod Med. 2015;60(5-6):194-198.

11. Berman JM, Puscheck EE, Diamond MP. Full-term vaginal live birth after laparoscopic radiofrequency ablation of a large, symptomatic intramural fibroid: a case report. J Reprod Med. 2012;57(3-4): $159-163$.
International Journal of Women's Health

\section{Publish your work in this journal}

The International Journal of Women's Health is an international, peerreviewed open-access journal publishing original research, reports, editorials, reviews and commentaries on all aspects of women's healthcare including gynecology, obstetrics, and breast cancer. The manuscript management system is completely online and includes

\section{Dovepress}

a very quick and fair peer-review system, which is all easy to use. Visit http://www.dovepress.com/testimonials.php to read real quotes from published authors.

\footnotetext{
Submit your manuscript here: http://www.dovepress.com/international-journal-of-womens-health-journal
} 